\title{
"Don't bother about me". The grief and mental health of bereaved adolescents
}

\section{Karl Andriessen, Jane Mowll, Elizabeth Lobb, Brian Draper, Michael Dudley \&} Philip B. Mitchell

To cite this article: Karl Andriessen, Jane Mowll, Elizabeth Lobb, Brian Draper, Michael Dudley \& Philip B. Mitchell (2018): "Don't bother about me". The grief and mental health of bereaved adolescents, Death Studies, DOI: 10.1080/07481187.2017.1415393

To link to this article: https://doi.org/10.1080/07481187.2017.1415393

ted author version posted online: 24

Jan 2018.

Submit your article to this journal $\pi$

III Article views: 14

Q View related articles $\sqsubset$

View Crossmark data $[7$ 


\title{
“Don't bother about me". The grief and mental health of
}

\section{bereaved adolescents}

\author{
Karl Andriessen
}

School of Psychiatry, University of New South Wales, Randwick, NSW, Australia

Jane Mowll

School of Social Sciences, University of New South Wales, Sydney, NSW, Australia

\author{
Elizabeth Lobb
}

Calvary Health Care Kogarah and Cunningham Centre for Palliative Care, Kogarah, NSW,

Australia

School of Medicine, University of Notre Dame, Sydney, Australia

Brian Draper

School of Psychiatry, University of New South Wales, Randwick, NSW, Australia

Michael Dudley

School of Psychiatry, University of New South Wales, Randwick, NSW, Australia

Philip B. Mitchell

School of Psychiatry, University of New South Wales, Randwick, NSW, Australia 
Address correspondence to Scientia Professor Philip B. Mitchell, School of Psychiatry, University of New South Wales, Black Dog Institute, Hospital Rd, Randwick 2031, NSW, Australia. Tele: +61 29382 3711. E-mail: p.mitchell@unsw.edu.au

\begin{abstract}
Death of a relative or friend is a potentially disruptive event in the lives of adolescents. To provide targeted help, it is crucial to understand their grief and mental health experiences. Thematic analysis of 39 semi-structured telephone interviews yielded two themes: Grieving apart together, and Personal growth. High self-reliance and selective sharing were common. Feelings of guilt and 'why' questions seemed more pronounced among the suicide bereaved. There was strong evidence of personal growth, increased maturity and capacity to deal with personal mental health/suicidality. Despite its devastating effects, experiencing a death can be a catalyst for positive mental health.
\end{abstract}

KEYWORDS: adolescent, bereavement, death, grief, mental health, suicide

Death among relatives or friends is a relatively frequent experience in the lives of adolescents. In Western countries, about $4 \%$ of adolescents lose a parent before the age of 18 (Berg, Rostila, \& Hjern, 2016; Rostila, 2015); almost half (48\%) of US adolescents experience the death of a family member or a friend during the past year (Rheingold et al., 2004), and lifetime prevalence of experiencing the death of a relative or a friend among adolescents has been estimated at $78 \%$ (Harrison \& Harrington, 2001). A meta-analysis indicated that $4.6 \%$ of adolescents are exposed to a suicide in the past year and 18\% during their lifetime (Andriessen, Rahman, Draper, Dudley, \& Mitchell, 2017b). 
Experiencing a death, especially of a parent, is the most stressful event in the life of children and adolescents (Hollingshaus \& Smith, 2015). Although bereavement after any death is a potentially disruptive life event with consequences in physical and mental health, relationships, and social functioning, it can also be associated with personal growth in terms of increased appreciation of life, of others, and emotional strengths (Balk, 2014). Suicide bereavement is a risk factor for adverse health, mental health, and suicidal behavior (Pitman, Osborn, Rantell, \& King, 2016). Although the course and duration of grief after suicide may resemble other types of bereavement, some characteristics, such as feelings of guilt, shame, stigma, or rejection, may be more pronounced, and may render suicide bereavement more challenging for vulnerable individuals (Andriessen, Krysinska, \& Grad, 2017a).

Less is known specifically about the aftermath of suicide among bereaved adolescents compared to bereaved adults, or compared to adolescents bereaved by other causes of death (Cerel \& Aldrich, 2011). A recent systematic review indicated that a suicide death impacts adolescents' grief, mental health, at-risk behaviours, and suicidal behavior (Andriessen, Draper, Dudley, \& Mitchell, 2016). However, the context in which the suicide occurred, including the psychological closeness of the relationship between bereaved and deceased persons, personal and familial mental health history, social support and quality of the remaining relationships, may affect the grief and mental health of the bereaved adolescents (Andriessen et al., 2016).

To develop suitable support for bereaved adolescents it is essential to know how they experience their grief and mental health. In qualitative studies, adolescents reported marked feelings of guilt, (self-)blame, anger, depression, at-risk behaviours, suicidality, and changes in relationships (Bartik, Maple, Edwards, \& Kiernan, 2013; Hoffmann, Myburgh, \& Poggenpoel, 2010). Adolescent girls stated that the suicidal death of their father was a life-changing experience 
(Ratnarajah \& Schofield, 2008; Silvén Hagström, 2013). After a suicide cluster, adolescents reported both feelings of shock and guilt, as well as increased valuing of life (Heffel, Riggs, Ruiz, \& Ruggles, 2015). Although these studies provide insights in the adolescents' experiences, their limitations include small sample size, unequal gender distribution, lack of variation in types of relationships in the study groups, and lack of comparison group. Also, only two studies specifically focused on adolescents (Heffel et al., 2015; Silvén Hagström, 2013), whereas the other studies included childhood or young adulthood experiences as well (Bartik et al., 2013; Hoffmann et al., 2010; Ratnarajah \& Schofield, 2008).

The present qualitative study investigated grief and mental health experiences of adolescents bereaved by suicide or other causes of death. The results regarding help-seeking will be reported in a companion paper (Authors, submitted).

\section{Method}

\section{Study design and sampling}

The study was conducted according to the Consolidated Criteria for Reporting Qualitative Research (Tong, Sainsbury, \& Craig, 2007). We used semi-structured telephone interviews with a maximum variation purposive sample (Bryman, 2012), with adolescents aged 12 to 18 years old. Eligibility included having a family member or a friend die through suicide or other cause of death when participants were aged between 12 and 18 years old, and experiencing the death between 6 months and 10 years prior to interview. There was no restriction regarding kinship/type of relationship, or geographical location within Australia. The sample was stratified to include a similar number of adolescents bereaved by suicide and other causes of death. Participants were recruited from June 2015 to July 2016 through a wide variety of bereavement, health and youth 
organizations, and announcements on posters, flyers and websites. Interviewees received a $\$ 20.00$ gift voucher as reimbursement for their time.

Initially, 155 adolescents, parents, and counsellors expressed interest in the study, and received an introductory letter, the study flyer, and a consent form to be signed and returned prior to participation. In all, 39 adolescents (30 girls) participated. Reasons for not participating included lack of time $(n=54)$, not eligible $(n=30)$, and unknown $(n=35)$. Participants were aged between 13 and 27 years old at the time of the interview $(M=20.59, S D=3.24)$. They had experienced a total of 51 deaths; 9 experienced more than one death. About half of the participants $(n=19)$ had experienced a suicide death. The deaths occurred on average five years before the interview $(M=$ 4.92, $S D=3.08)$. Age at loss varied between 13 and 18 years $(M=15.39, S D=1.78)$. The deceased persons were a grandparent $(n=12)$, a parent $(n=6)$, brother $(n=4)$, friend/school friend/best friend ( $n=12)$, and family friend $(n=4)$. There was no difference between type of relationship and cause of death. More details of the sample are available upon request.

\section{Procedure}

A semi-structured interview guide was based on the current scientific literature (Andriessen et al., 2016). The lead questions, available from the first author on request, were open-ended, allowing for probes, and follow-up (Bryman, 2012). Typically, interviews started with an openended question, "Could you tell me a bit about the person who you have lost, who has died?" Typically interviews ended with a question about whether interviewees could recommend something to other adolescents. After the first six interviews, the research team evaluated the interview scheme, added a few questions on memories and continuing bonds, and rephrased 
questions about meaning-making into questions regarding lessons learned. We recorded interviews, had them professionally transcribed, and checked anonymised transcripts for accuracy.

The interviewer (KA) was a social worker and $\mathrm{PhD}$ candidate with substantial experience in death and suicide-related telephone crisis intervention. The interviewer recorded field notes after the interviews, and during listening or reading the transcripts. Interviews lasted $17-75$ minutes $(M=43.36, S D=15.13)$. The diverse experience of the research team including social work, psychiatry, and psychology and behavioural science ensured reflexive balance in analysis.

\section{Data analysis}

Three researchers (KA, EL, JM) created a codebook, including deductive codes based on theory and literature (Andriessen et al., 2016), for example, related to closeness of the relationship, and inductive codes based on the content of the first interviews, for example, disclosing grief experiences to others. Our perspective was social constructionism, which is concerned with how people create knowledge of reality (Breckenridge, Jones, Elliott, \& Nicol, 2012), and postulates that people socially construct problems and experiences within a relational and social rather than an individual or intrapsychic context (Bryman, 2012; Neimeyer, Klass, \& Dennis, 2014). Hence, the analysis considered factual information, as well as how participants shared their experiences in their social networks and gave meanings to them. The thematic analysis involved reading and re-reading the data, producing initial codes, and grouping codes in potential themes, which we reviewed and refined against the data (Braun \& Clarke, 2016). We used NVivo 10 (QSR, 2014) and held regular team discussions to minimise researcher bias.

\section{Ethical considerations}


The project was approved by the Human Research Ethics Committee of the University of New South Wales, Australia (HC15088). The Black Dog Institute, Orygen - National Centre of Excellence in Youth Mental Health, the Catholic Education Office of Sydney, and the State Coroner of New South Wales approved recruitment through their networks, and the South Eastern Sydney Local Health District approved recruitment through the local adolescent mental health clinic at Prince of Wales Hospital.

All potential research participants contacted the researcher (KA) to express interest in the study. During that initial contact, the researcher explained the purpose and the methods of the study, the voluntary basis and confidentiality, what would be required from the participant, potential risks or benefits, their prerogative to pause or stop at any time, and any other questions or concerns.

Based on the National Statement on Ethical Conduct in Human Research (Commonwealth of Australia, 2014), we used different consent procedures depending on the participant's age. For those aged 12-15, we obtained parental/guardian consent. For those aged 16-17, who potentially have the maturity to understand the research and consent, the researcher decided at the end of the initial contact whether a parent/guardian should consent. When in doubt, the researcher sought a second opinion from a co-investigator. During the initial telephone contact, the researcher encouraged the adolescent to talk about the research participation with a parent/guardian, before and/or after the interview, or to have a confidant sit with them during the interview. Parents/guardians who did not need to consent could contact the researchers to talk about the purpose and their adolescent's involvement.

\section{Results}


The analysis resulted in two main themes reflecting the participants' grief and mental health experiences. The first main theme Grieving apart together, concerns the ways adolescents characterised their grief as a tension between a very personal experience on the one hand, and a relational experience with family and peers, and for some a continued relationship with the deceased, on the other. The second major theme Personal growth included life lessons and selfcare. Examples follow of each theme; participants' names are fictional.

\section{Grieving apart together}

This theme had three aspects: Experiencing the grief, Grief in relation to others, Grief in relation to the deceased. A first aspect was adolescents' experiences of grief, which encompassed initial reactions and understanding and later reactions. Adolescents typically learned of the death from parents/family, school, or friends. A few were present when the person died. In suicide deaths, a few discovered the death by finding the body. Some were not told the truth immediately, which they experienced primarily as a parental protective measure. One interviewee wanted adults to be more careful during family conversations as the adolescent could overhear potentially distressing details of the suicide, especially if the family wanted to protect the adolescent from such details.

Participants commented on how the expectedness or unexpectedness of the death impacted their feelings. Participants who experienced more than one death could distinguish differences regarding expectedness. Some interviewees explicitly linked the initial feelings of shock and unexpectedness of the death to their young age at the time of death: 
Really shocked. I remember shock being the primary emotion just because it was such a sudden death and I guess at my age there's an expectation that your life is just starting and for it to be cut short so quickly is really unfortunate. (Jessy, friend accident).

Another participant said,

I guess it came quite suddenly because nobody expected it, which is why it [was] quite a bit of a shock to a lot of our family. Especially for us, because we were pretty young-ish, I guess. Because we were like 14 at the time, so weren't quite expecting anything like that for someone who you don't really see as being a sick or old relative. (Sara, aunt suicide)

A few interviewees retrospectively recognized possible indications of suicide, such as suicide attempts, but did not recognize these signs at that time. A few interviewees experienced the suicide as expected. The most common initial reaction after any death was shock; other reactions were feelings of sadness, surprise, disbelief, being overwhelmed or confused, and behaviors of crying and sometimes screaming. In the months after the death, the most common reactions were sadness and missing the deceased person, sometimes accompanied by yearning, rumination, physical pain, numbness, blame, or regret.

Anger was common and strong, irrespective of the cause of death. The objects of the anger varied and included themselves, the deceased person, others, the situation, or the world at large. Interviewees felt that the deceased person let them down, betrayed, or rejected them. Some interviewees related their strong feelings of anger to the apparent insufficiency of other coping skills at that age. For example,

You're at an age where you're angry anyway I guess. You're a teenager, ... you're learning coping mechanisms at that stage. When you haven't got an emotional backing from anyone, 
or you haven't got an adult who you can go, hey, it's okay to feel angry, it's okay to feel like shit, then you find another alternative [i.e. illicit drugs] so it stops hurting. (Beatrice, best friend suicide)

Some interviewees explicitly stated not feeling anger, for example because they saw themselves not in a position to judge the deceased person. Many interviewees reported a strong sense of moral or existential injustice. Regardless of the cause of death, several adolescents experienced the death as not right, something that should not have been possible. For example,

I suppose I was angry that it had happened all to us. Our family is very close and it didn't seem right that such a wonderful person could be taken when she still had so much to do with her life. (Helen, grandmother and uncle natural causes, and great aunt accident)

A few adolescents became anxious that someone else close to them might die. This reaction seemed related to the unexpectedness of the death, and though rare, it was persistent and sometimes related to a broader anxiety. Some adolescents reported feeling uncertain about how they should feel or behave after the death, especially if it was their first major loss experience. Feeling unprepared to deal with the death they compared their reactions to others.

I never cried, so I never showed the emotion that my dad did and my sister did. I found that a bit troubling, I think. Obviously, I did love him very much and I found it bizarre, this having been the first death I'd been in such close proximity to, to not display what I considered to be the necessary emotion. But that's not to say that I don't miss him. (Leo, grandfather illness)

Some interviewees related their uncertainty about how to deal with the death to their education, or to having parents shield them from death and loss. These adolescents preferred more 
openness and a chance to hear details about the deaths, and believed that open discussion might better equip them to deal with death and their grief reactions.

Realising that the way you react is natural. You shouldn't feel ashamed of how you react. ... I wish I had that kind of education and support as a kid, and I sometimes wonder what it would have been like for me if I had been helped. Maybe I would have had easier teenage years. (Rebecca, aunt-godmother suicide)

Some adolescents also experienced positive emotions, which provided consolation. Positive feelings included gratitude and relief that the person's suffering ended, and gratefulness for having known the person. The intensity of the grief varied over time and never completely went away. They expected that, rather than completely dissolving, their grief would continue waxing and waning.

Some grief reactions were much more common among those bereaved by suicide, including guilt and 'why' questions, often related to their personal involvement and the perceived preventability of the suicide. For example, Steve, whose cousin and two friends died by suicide, said: "there are so many questions with why, why did they do it, why couldn't they get help." Pauline noted:

That just frustrated me for such a long time, because I think, why didn't you call me? Why didn't you message me? Why didn't you just tell me? Like because I was always there, why couldn't he just tell me? (boyfriend suicide)

Some interviewees felt that the importance of the "why"-question diminished over time. The bereaved adolescent may need some distance to acknowledge its complex nature: 
You definitely feel like you're trying to solve the puzzle. But perhaps at the moment the puzzle doesn't need to be solved. The puzzle just needs to be left until it has passed, and you have acknowledged it and then you can look at it in a [calm] manner because - or one person thinks one day is almost definitely not the same as the other day. That is why the reflection time is needed just to understand it. (Garry, ex-girlfriend suicide)

Conversely, some of the suicide bereaved adolescents explicitly stated that they did not feel guilty, sometimes as a result of painstakingly looking back at the suicide and their relationship with the deceased person. As Pauline stated: "Nobody can tell the future. You didn't know that this was going to happen.”

In brief, adolescents may experience a lasting impact of the death. While feelings of shock and sadness are common, adolescents also felt anger and injustice, which some participants related to their age. Positive emotions such as relief and gratitude provided some consolidation. Feelings of guilt and why-questions were pronounced among those bereaved by suicide. Adolescents expressed a view that open discussions with parents might help them better understand their grief reactions.

A second aspect was grief in relation to others. Interviewees commonly reported concern for the well-being of other family members and friends irrespective of the cause of death, even if this concern jeopardized adolescents' chances of receiving support. Focusing on the well-being of others sometimes distracted them from their own feelings. Sara said: "to be able to take care helped me kind of be a little bit less sad, because I had something to do." (aunt suicide). For example, 
I was just about being strong for my family because they were suffering as well and I didn't want to show them that I was hurting. So I just focused on protecting them and supporting them instead of displaying my own feelings. (Anne, friend suicide, aunt illness)

Indeed, most of the bereaved adolescents were very selective, and shared their experiences only with specific relatives or friends who were close and/or who had a similar experience. Notably, being selective did not contradict with being open with those selected relationships. However, as one interviewee cautioned: "The ones who put up the best facades are the ones who struggle the most." (Rebecca, aunt-godmother suicide).

Interviewees reported a variety of reasons for their selective self-disclosure, related to themselves, others, or the familial/cultural context. The need not to talk to others about their grief was often accompanied by strong feelings of self-reliance, or the perception that others were not available. Some interviewees specifically related their self-reliance and reluctance for sharing to their developmental stage. One interviewee stated: "Teenagers tend to think that the world just revolves around them and their feelings at the time. Not in a selfish way, but they don't see the whole picture." (Beatrice, best friend suicide).

Others lacked sufficient language to express their feelings or experienced that it was too painful to talk about the death, especially when it was still recent. However, they felt it was easier over the years. Several interviewees reported discomfort if too many other people would have known about their loss or their grief feelings. They considered it as a private matter, and they did not want to stand in the spotlight or be different. For example, 
I just didn't want to talk about it. I felt like everyone was looking at me thinking that ... It made me feel like a bit of a zoo exhibit, like everyone was looking at me like oh that poor girl she's going to go off the rails. (Maria, mother illness)

A few interviewees gave other reasons for holding back, including anxiety, mistrust, and wanting to forget. Some reported that non-bereaved friends did not know how to react and avoided the topic. Sometimes it helped when the bereaved adolescent explained to others how to react. Above all, bereaved adolescents appreciated heartfelt and genuine reactions of others, and noted that if others had asked about their grief, they might have opened up. For example,

It was always just look at how I'm feeling, look at the way I'm walking, and interpret it and maybe ask me beyond just how was school. How about just ask me if I'm okay? (Emily, two family friends and grandfather illnesses)

Some of the interviewees with Asian background said that not talking about emotions or personal experiences was a part of their culture and was a barrier for talking about the death or seeking help when they felt distressed or suicidal. Other interviewees reported that their family relational style irrespective of the cultural or ethnic background played an important role in disclosing their grief experiences. Having troubled or fading relationships, or being reserved, prevented bereaved adolescents from sharing their experiences within the family.

To highlight the major findings of this section: adolescents shared their grief experiences with a few selected confidants (a friend or a family member), with the exclusion of others, and experienced distractions as important as talking about their grief. Adolescents had high levels of self-reliance, and some preferred to take care of others even if this would minimise their own chances of receiving support. They appreciated heartfelt reactions, but not stand in the spotlight. 
A third aspect was grief in relationship to the deceased person. Most of these bereaved adolescents, irrespective of the cause of death, experienced or maintained an ongoing inner relationship with the deceased person. Sometimes this continuing bond was a grief reaction; sometimes it was a way of dealing with the grief. Continuing bonds focused on both the loss and the past, for example, through keeping mementos, and on the future and reorganizing their lives. These adolescents experienced the continuing bonds in various ways, including reminding and doing things that the deceased person would have liked, either alone or with others. For some, the continuing bond was private, for others it was shared. Sometimes the continuing bond took the form of a ritual, perhaps linked to dates (such as birthdays) or places (such as the grave). Some interviewees perceived the deceased person as a guardian angel, or expected to be reunited in an afterlife. A few interviewees engaged in altruistic acts to honor the deceased person, including helping others or raising awareness for suicide prevention. Others perceived the deceased person as a source of inspiration, an inner voice, or a role model, internalizing values and characteristics of the deceased. One interviewee said,

It's more a goal really that - so whenever if I want to set a target in my studies [unclear] I keep in mind about the goal - okay - I'm going to ... being a teacher but ... I'll be the one that makes a difference, just like my grandpa. (Rachel, grandfather illness)

For most interviewees, the continuing bond was a positive, meaningful experience, allowing them to cope with the grief, to continue with their life, and simultaneously honor the life and the values of the deceased person. However, a few adolescents had painful or distressing experiences, and a few were ambivalent.. A few interviewees explicitly linked their insight into the importance of the continuing bond with the deceased to growing older, believing that as a younger person they were unable to appreciate the value of such bond.. One interviewee said, 
I feel like he is really important and he's so special and I love him so much still, that I think it would be such a shame for me not to be proud of myself and to help other people and to do all the things that I love in life, because he never even got that chance. But I think it's only when you're older you realise that stuff you know? When you're young it's so messy and you don't ever see - when I was 16 I would never have seen my life being this good. I could never vision that, you know? (Pauline, boyfriend suicide)

To sum up this section, adolescents experienced the continuing bond in various ways. While most adolescents experience the continuing bond is a positive, supportive way, some felt ambiguous about it.

\section{Personal growth}

Two important subthemes related to the theme of personal growth. The first subtheme Life lessons refers to how the death changed their lives. Interviewees experienced lasting positive changes of their perception of self, relationships, or life. Some experienced the death as a beforeand-after landmark in their life. In addition, Self-care related the confrontation with death, suicide and mental health issues.

Life lessons included increased appreciation of life and relationships, often bolstered by an awakened and profound awareness of the fragility and impermanence of life, and an increased empathy or compassion for others. One interviewee stated: "Because it happened at such a young age it taught us all how bad things can be" (Beatrice, best friend suicide). Several interviewees experienced a stronger appreciation of life through exploring new possibilities, formulating aspirations for the future, setting priorities, and appreciating each day. They reported a sense of self-determination on how to live their life, and/or took up new responsibilities. Some interviewees 
believed the appreciation of life strengthened as they grew older than their deceased friend or sibling. For example,

I don't think without [friend] dying that I would have cared this much about other people's feelings, or I would have as much empathy as I do. I honestly don't think I would. I think I'm stronger. I think I deal with situations a lot better than I would if I hadn't been and I think I have more ambition because of it as well. I want to be a lot of things for the both of us, for me and him. I want to be successful and I want to be happy and I want me to be somebody that he would be really proud of. (Pauline, boyfriend suicide)

Several interviewees experienced growing up faster and being more mature than others without such a major loss. Some interviewees experienced increased personal strength through an increased capacity to accept the loss. For example,

I think I've grown more - I think now I've experienced something quite profound and quite moving, which I don't really get to experience a lot of firsthand. Yeah, I think it's made me more optimistic about death, in a way, about what death is. (Leo, grandfather illness).

As such, throughout the grief process, adolescents made meaning of the death through life lessons learned from the loss. Adolescents became more aware of the fragility of life, and the importance of relationships. This resulted in increased empathy, maturity, and setting of priorities and goals for the future.

The theme of Self-care included increased self-awareness, self-confidence, self-reliance and self-care of participants' own mental health or suicidality, along with a broader feeling of resilience to handle difficult situations. Irrespective of the cause of death several adolescents experienced mental health problems, usually anxiety and mood disorders, or, to a lesser degree, 
eating disorders. Some adolescents experienced mental health issues themselves or in the family, including suicidal behavior, before the loss, some at a very young age. For some adolescents the death exacerbated their mental illness; and some adolescents developed suicidal ideation or behavior. Sometimes the suicidality appeared to be an impulsive reaction triggered by the death. Nevertheless, it still involved an interaction of various factors, including social factors, mental health, grief feelings and the impact of the death of a close person. For some adolescents, receiving a mental health diagnosis helped them understand their mental condition; and for some, experiencing a suicide helped them cope with their own mental health, or prevented them from attempting to take their own life. To experience and witness the devastating effects of suicide on others, adolescents realized that suicide was not their way of dying. Adolescents reported that holding such a negative attitude towards suicide had a protective effect.

I wish it had never happened, but at the same time - I'm not glad it happened, but because it happened I can deal with it. I learnt something from it, how it affects people. It stopped me from killing myself, I guess. So I wish it never happened. I wish she was still here, that they were both here, but I learnt that I can deal with it. (Rebecca, aunt-godmother suicide)

Summarizing the major finding of this section: despite the undeniable devastating effects adolescents experienced from a (suicide) death, many adolescents also experienced positive effects with insights into their own mental health and suicidality to the extent that adolescents experienced a suicide preventive effect.

\section{Discussion}

The study contributes important insights into the grief experiences of bereaved adolescents. As recommended in the literature (Andriessen et al., 2016) and adopting a social constructionist 
perspective on grief (Neimeyer et al., 2014), we investigated the adolescents' experiences in a relational and mental health context. These bereaved adolescents experienced lasting grief and mental health ramifications irrespective of the cause of death or kinship with the deceased. Psychological closeness to the deceased person appeared to be an important factor (Servaty-Seib \& Pistole, 2007). In common with other studies, participants reported a spectrum of grief reactions, such as shock, sadness, missing, anger and a fear that others may die as well (Bartik et al., 2013; Hoffmann et al., 2010). Importantly, in this study, participants also evidenced positive feelings of gratitude and relief. Participants appreciated openness from parents, conversely feeling negative or ambivalent about being shielded from the death.

In addition, a noteworthy finding is the presence of strong feelings of anger and injustice which adolescents related to their age at the time of death. Identity formation and searching for ways to relate to the world are important developmental tasks (Balk, 2014). Hence, experiencing the death of a close person is a potentially disruptive experience, which may engender feelings of anger and injustice.

The study found few differences between suicide bereavement and other causes of bereavement. Similar to adult studies, feelings of guilt and struggles with the "why"-question seem more pronounced among adolescents bereaved by suicide (Andriessen et al., 2017a; Jordan \& McIntosh, 2011). This finding is important as adolescents can experience the why-questions as unsolvable and leading to rumination, while negative thinking and rumination may perpetuate suicidal thinking (O’Connor \& Nock, 2014).

The study revealed unique findings on the relational aspects of grief. The bereaved adolescents were very selective, and shared their experiences with a few specific confidants only. Also, high levels of self-reliance and wanting to manage for themselves were common. At the 
same time, they were very considerate and loyal to grieving family members, an aspect also found in a few other studies (Dyregrov \& Dyregrov, 2005; Sveen, Kreicbergs, Melcher, \& Alvariza, 2016), suggesting the relevance of attachments and caring for carers to mutual survival in crisis. The dual attitude of being there for others while minimising themselves may have contributed to feeling overlooked regarding their grief and mental health. These contradictions in dealing with relationships relate to the adolescent developmental task of separation from parents and gaining independence. The importance of the relational context to deal with grief lends credibility to the study of grief through a social constructionist perspective (Neimeyer et al., 2014).

In addition to the importance of the relationships with family and friends, this study showed the ongoing importance of the relationship with the deceased. Adolescents experienced the continuing bond in various ways, either as a grief reaction or a way of dealing with the grief. Hence, the causal relation between the grief and the continuing bond experience is not always clear (Field \& Wogrin, 2011). Positive, helpful experiences of continuing bonds are commonly reported by other studies (Hansen, Sheehan, Stephenson, \& Mayo, 2016; Root \& Exline, 2014). However, adolescents in this study reported that continuing bonds were sometimes distressing or ambiguous, as suggested by recent literature (Root \& Exline, 2014; Stroebe, Schut, \& Boerner, 2010). As such, for some of the bereaved persons it may be more beneficial to relinquish than to maintain bonds (Root \& Exline, 2014). In this perspective, it is noted that the grief experience of some participants resembled the Dual-Process model of grief in which the bereaved oscillates between the grief experience and reorganization of life (Stroebe, Folkman, Hansson, \& Schut, 2006).

For many adolescents the death signified a catalytic life event, and they developed a more thoughtful, and in their experience, a more mature view on life and relationships. Notwithstanding that the death may have exacerbated the mental health of the bereaved adolescents (Bolton et al., 
2016; Stikkelbroek, Bodden, Reitz, Vollebergh, \& van Baar, 2016), it was also 'a wake-up call'. Many adolescents experienced a positive effect in dealing with their own mental health, and in their experience, the death had a suicide preventive effect. This unique insight adds to findings from other studies that found no increased suicide risk after the suicide of a friend (Brent, Moritz, Bridge, Perper, \& Canobbio, 1996; Feigelman \& Gorman, 2008). Our findings suggest that among adolescents the death of any close person can have positive effects in increased maturity, mental health and/or suicide prevention. Future research may further clarify which factors are likely to contribute to these positive effects among bereaved adolescents.

Limitations of this study include reliance on self-report from voluntary participants, which may entail selection and recollection bias. As we interviewed mostly girls, the findings may apply less to adolescent boys. Also, although interviewees had ample opportunity to provide comments, it is possible that they did not share some important experiences.

Despite these limitations, the study provided clear insights into the complex and multifaceted grief of adolescents. Adolescents experience a profound and potentially lasting impact of the death of a family member or friend, and their experience can vary over time. Feelings of guilt and the "why"-question seemed more pronounced among those bereaved by suicide. The psychological closeness of the relationship, and the familial context may affect the grief of the bereaved adolescent. Grief and mental health experiences are intertwined especially in cases of personal or familial mental health history.

From the perspective of clinicians and family caregivers, adolescents' reluctance to share their grief may relate to developmental contexts in which the adolescent gains independence from the family, develops self-reliance, and opts to share with a few confidants, for example a friend or 
a parent. Timing and type of support should not be limited to talk-therapy, and should be sensitive to the pains and strengths of the bereaved adolescent to reach those in need of support.

Importantly, the study found strong evidence of personal growth, increased maturity and improved capacity to deal with own mental health and suicidality. Indeed, despite the fact that experiencing a (suicide) death may have devastating effects, it could be a catalyst for positive mental health.

\section{Acknowledgments}

We are most grateful to the participants for sharing their experiences, and to all organizations and individuals who helped with recruitment. The study was supported by the Anika Foundation for Adolescent Depression and Suicide. The funding body had no role in the design of the study, the collection, analysis and interpretation of data, the writing of the report, and the decision to submit it for publication.

\section{References}

Andriessen, K., Draper, B., Dudley, M., \& Mitchell, P. B. (2016). Pre-and postloss features of adolescent suicide bereavement: A systematic review. Death Studies, 40, 229-246. doi:10.1080/07481187.2015.1128497

Andriessen, K., Krysinska, K., \& Grad, O. (2017a). Current understandings of suicide bereavement. In K. Andriessen, K. Krysinska, \& O. Grad (Eds.), Postvention in action: The international handbook of suicide bereavement support (pp. 3-16). Gottingen/Boston: Hogrefe.

Andriessen, K., Rahman, B., Draper, B., Dudley, M., \& Mitchell, P. B. (2017b). Prevalence of exposure to suicide: A meta-analysis of population-based studies. Journal of Psychiatric Research, 88, 113-120. doi:10.1016/j.jpsychires.2017.01.017

Balk, D. E. (2014). Dealing with dying, death, and grief during adolescence. New York, NY: Routledge.

Bartik, W., Maple, M., Edwards, H., \& Kiernan, M. (2013). Adolescent survivors after suicide. Australian young people's bereavement narratives. Crisis, 34, 211-217. doi:10.1027/02275910/a000185 
Berg, L., Rostila, M., \& Hjern, A. (2016). Parental death during childhood and depression in young adults-a national cohort study. Journal of Child Psychology \& Psychiatry, 57, 1092-1098. doi:10.1111/jcpp. 12560

Bolton, J. M., Au, W., Chateau, D., Walld, R., Leslie, W. D., Enns, J., ... Sareen, J. (2016). Bereavement after sibling death: A population-based longitudinal case-control study. World Psychiatry, 15, 59-66. doi:10.1002/wps.20293

Braun, V., \& Clarke, V. (2016). Thematic analysis. Retrieved November 4, 2016, from https://www.psych.auckland.ac.nz/en/about/our-research/research-groups/thematicanalysis.html

Breckenridge, J., Jones, D., Elliott, I., \& Nicol, M. (2012). Choosing a methodological path: Reflections on the constructivist turn. Grounded Theory Review, 11, 64-71.

Brent, D. A., Moritz, G., Bridge, J., Perper, J., \& Canobbio, R. (1996). Long-term impact of exposure to suicide: A three-year controlled follow-up. Journal of the American Academy of Child \& Adolescent Psychiatry, 35, 646-653. doi:10.1097/00004583-199605000-00020

Bryman, A. (2012). Social research methods (4th ed.). Oxford, UK: Oxford University Press.

Cerel, J., \& Aldrich, R. S. (2011). The impact of suicide on children and adolescents. In J. R. Jordan \& J. L. McIntosh (Eds.), Grief after suicide: Understanding the consequences and caring for the survivors (pp. 81-92). New York, NY: Routledge.

Commonwealth of Australia. (2014). National statement on ethical conduct in human research 2007 (Updated 2014). Canberra: Author.

Dyregrov, K., \& Dyregrov, A. (2005). Siblings after suicide, "The forgotten bereaved". Suicide \& Life-Threatening Behavior, 35, 714-724. doi:10.1521/suli.2005.35.6.714

Feigelman, W., \& Gorman, B. S. (2008). Assessing the effects of peer suicide on youth suicide. Suicide \& Life-Threatening Behavior, 38, 181-194. doi:10.1521/suli.2008.38.2.181

Field, N. G., \& Wogrin, C. (2011). The changing bond in therapy for unresolved loss: An attachment theory perspective. In R. Neimeyer, D. Harris, H. Winokuer, \& G. Thornton (Eds.), Grief and bereavement in contemporary society: Bridging research and practice (pp. 37-46). New York, NY: Routledge.

Hansen, D. M., Sheehan, D. K., Stephenson, P. S., \& Mayo, M. M. (2016). Parental relationships beyond the grave: Adolescents' descriptions of continued bonds. Palliative Supportive Care, 14, 358-363. doi:10.1017/S1478951515001078

Harrison, L., \& Harrington, R. (2001). Adolescents' bereavement experiences. Prevalence, association with depressive symptoms, and use of services. Journal of Adolescence, 24, 159-169. doi:10.1006/jado.2001.0379

Heffel, C. J., Riggs, S. A., Ruiz, J. M., \& Ruggles, M. (2015). The aftermath of a suicide cluster in the age of online social networking: A qualitative analysis of adolescent grief reactions. Contemporary School Psychology, 19, 286-299. doi:10.1007/s40688-015-0060-z

Hoffmann, W. A., Myburgh, C., \& Poggenpoel, M. (2010). The lived experiences of lateadolescent female suicide survivors: 'A part of me died'. Health SA Gesondheid, 15, 1-9. doi:10.4102/hsag.v15i1.493

Hollingshaus, M. S., \& Smith, K. R. (2015). Life and death in the family: Early parental death, parental remarriage, and offspring suicide risk in adulthood. Social Science \& Medicine, 131, 181-189. doi:10.1016/j.socscimed.2015.02.008

Jordan, J. R., \& McIntosh, J. L. (Eds.), (2011). Grief after suicide: Understanding the consequences and caring for the survivors. New York, NY: Routledge. 
Neimeyer, R., Klass, D., \& Dennis, M. R. (2014). A social constructionist account of grief: Loss and the narration of meaning. Death Studies, 38, 485-498. doi:10.1080/07481187.2014.913454

O'Connor, R. C., \& Nock, M. K. (2014). The psychology of suicidal behaviour. Lancet Psychiatry, 1,73-85. doi:10.1016/S2215-0366(14)70222-6

Pitman, A. L., Osborn, D. P., Rantell, K., \& King, M. B. (2016). Bereavement by suicide as a risk factor for suicide attempt: A cross-sectional national UK-wide study of 3432 young bereaved adults. BMJ Open, 6(1), e009948. doi:10.1136/bmjopen-2015-009948

QSR. (2014). NVivo 10 for Windows. [Computer software]. QSR International Pty Ltd.

Ratnarajah, D., \& Schofield, M. J. (2008). Survivors' narratives of the impact of parental suicide. Suicide \& Life-Threatening Behavior, 38, 618-630. doi:10.1521/suli.2008.38.5.618

Rheingold, A. A., Smith, D. W., Ruggiero, K. J., Saunders, B. E., Kilpatrick, D. G., \& Resnick, H. S. (2004). Loss, trauma exposure, and mental health in a representative sample of 12-17year-old youth: Data from the national survey of adolescents. Journal of Loss and Trauma, 9, 1-19. doi:10.1080/15325020490255250

Root, B. L., \& Exline, J. J. (2014). The role of continuing bonds in coping with grief: Overview and future directions. Death Studies, 38, 1-8. doi:10.1080/07481187.2012.712608

Rostila, M. (2015). Commentary: Childhood parental loss and adulthood health: Discussing the role of parental cause of death, child's age at death and historical context. Social Science \& Medicine, 131, 190-192. doi:10.1016/j.socscimed.2015.03.012

Servaty-Seib, H. L., \& Pistole, M. C. (2007). Adolescent grief: Relationship category and emotional closeness. Omega: Journal of Death and Dying, 54, 147-167. doi:10.2190/M002-1541-JP28-4673

Silvén Hagström, A. (2013). 'The stranger inside': Suicide-related grief and 'othering' among teenage daughters following the loss of a father to suicide. Nordic Social Work Research, 3, 185-193. doi:10.1080/2156857X.2013.801877

Stikkelbroek, Y., Bodden, D. H., Reitz, E., Vollebergh, W. A., \& van Baar, A. L. (2016). Mental health of adolescents before and after the death of a parent or sibling. European Child \& Adolescent Psychiatry, 25, 49-59. doi:10.1007/s00787-015-0695-3

Stroebe, M. S., Folkman, S., Hansson, R. O., \& Schut, H. (2006). The prediction of bereavement outcome: Development of an integrative risk factor framework. Social Science \& Medicine, 63, 2440-2451. doi:10.1016/j.socscimed.2006.06.012

Stroebe, M., Schut, H., \& Boerner, K. (2010). Continuing bonds in adaptation to bereavement: Toward theoretical integration. Clinical Psychology Review, 30, 259-268. doi:10.1016/j.cpr.2009.11.007

Sveen, J., Kreicbergs, U., Melcher, U., \& Alvariza, A. (2016). Teenagers' reasoning about a parent's recent death in cancer. Palliative Supportive Care, 14, 349-357. doi:10.1017/S1478951515001054

Tong, A., Sainsbury, P., \& Craig, J. (2007). Consolidated criteria for reporting qualitative research (COREQ): A 32-item checklist for interviews and focus groups. International Journal for Quality in Health Care, 19, 349-357. doi:10.1093/intqhc/mzm042 